\title{
INFORMAÇÃO E ESPORTE: A INFORMAÇÃO ESPORTIVA E SUA RELAÇÃO COM CLUBESS DE FUTEBOL
}

\author{
INFORMATION AND SPORT: THE SPORTS INFORMATION \\ AND ITS RELATIONSHIP WITH FOOTBALL CLUBS
}

Carlos Francisco Bitencourt Jorge - bitencourt@gmail.com Doutorando em Ciência da Informação pela Universidade Estadual Paulista Júlio de Mesquita Filho (Unesp - Marília).

Marta Lígia Pomim Valentim - valentim@valentim.pro.br Doutora em Ciências da Comunicação pela Universidade de São Paulo (USP). Professora da Universidade Estadual Paulista Júlio de Mesquita

Filho (Unesp - Marília).

\section{RESUMO}

Introdução: Apresenta conceitos acerca da informação, bem como seu uso no contexto esportivo. Discorre sobre as relações entre a informação e o ambiente esportivo, mais precisamente em clubes de futebol, delimitando-a como informação esportiva.

Objetivo: Descreve a tipologia da informação esportiva, seus principais tipos, fontes e ambientes, visando uma maior compreensão sobre esse tipo de informação. Analisa as relações entre informação e ambiente esportivo, mais precisamente em clubes de futebol. Explica o comportamento informacional neste tipo de organização e o impacto deste para os processos de tomada de decisão.

Metodologia: Realizou-se uma pesquisa bibliográfica sobre as temáticas da pesquisa alinhada ao processo de observação direta nas atividades realizadas por um clube de futebol.

Resultados: Apresenta resultados relacionados a utilização da informação no processo decisório em diferentes níveis de um clube de futebol.

Conclusão: Demonstra a importância do uso da informação no contexto esportivo, bem como a delimitação das informações esportivas relacionadas aos clubes de futebol. Evidencia a informação esportiva como importante componente, responsável por propiciar diferenciais competitivos, visando gerar vantagem competitiva no contexto do esporte. 
Palavras-chave: Informação esportiva. Diferenciais competitivos. Inteligência competitiva. Clubes de futebol.

\section{INTRODUÇÃO}

Pode-se afirmar que existem diversas maneiras de interpretar e considerar as informações esportivas. A informação será compreendida no terreno esportivo, usando-se como base a definição de Davenport e Prusak (1998, p. 18): "Dados dotados de relevância e propósito".

Parte-se do pressuposto de que a informação está contida nas organizações em sua totalidade, isto é, em seus segmentos/departamentos e, até mesmo, no mercado em que a organização está inserida. Como observa Valentim (2006, p. 1214) destacando que as organizações possuem distintos ambientes informacionais e evidenciando os tipos de informações que podem ser encontrados em tais ambientes:

- Informação estratégica, que apoia o processo de tomada de decisão e possibilita à alta administração da organização definir e planejar as estratégias de ação de médio e longo prazo;

- Informação voltada ao negócio, que possibilita ao nível tático da organização definir ações de curto prazo, bem como observar oportunidades e ameaças para o negócio corporativo;

- Informação financeira, que apoia as atividades desenvolvidas pelos profissionais da área financeira para que processem estudos de custos, lucros, riscos e controles;

- Informação comercial, que subsidia as pessoas da área comercial nos processos relacionados à exportação e/ou importação de materiais, produtos e serviços; que subsidia também as pessoas da área jurídica no que diz respeito à legislação do país no qual se estabelece determinada transação comercial;

- Informação estatística, que subsidia várias áreas da organização, por meio se séries históricas, estudos comparativos, apresentando percentuais e/ou números relacionados ao negócio da organização;

- Informação sobre gestão, que atende as necessidades dos gerentes e executivos da organização no planejamento e gerenciamento de projetos, na gestão de pessoas etc.;

- Informação tecnológica, que tanto subsidia as pessoas da área de pesquisa e desenvolvimento (P\&D) na criação e no desenvolvimento de produtos, materiais e processos, por meio do monitoramento da concorrência referente às inovações de produtos, materiais e processos, como apoia a implantação dos sistemas de qualidade no ambiente organizacional; 
- Informação geral, que subsidia todas as áreas da organização, possibilitando aos profissionais, que nela atuam, atualização constante;

- Informação 'cinzenta' de qualquer natureza, para qualquer área e com qualquer finalidade de uso; esse tipo de informação não é detectado em buscas formais, podendo-se citar, como exemplo, colégio invisível, documentos confidenciais em difícil acesso, redes de relacionamento etc.

Tendo em vista as informações encontradas nos ambientes organizacionais destacadas por Valentim (2006), evidencia-se que no contexto esportivo existe a falta de informações voltadas diretamente ao esporte. Tais informações são importantes porque têm a finalidade de subsidiar as organizações e os indivíduos no âmbito esportivo e em diferentes atividades desempenhadas.

Clarke (2000 apud MONTEIRO; BOTELHO, 2009, p. 58) conceitua informação esportiva como:

[...] informação especializada, que diz respeito ao domínio específico das atividades físicas desportivas e do lazer, e que os usuários dos serviços estão cada vez mais exigentes com relação à eficácia do serviço e à boa adequação dos produtos de informação às suas necessidades.

A informação esportiva após sua seleção, análise e agregação de valor pode transformar-se em insumo estratégico no plano esportivo. As necessidades informacionais estão totalmente relacionadas ao ambiente ao qual ela é gerada, bem como às necessidades de uso desse segmento econômico.

Ao se analisar essa modalidade de informação é importante delimitá-la sob dois vieses. O primeiro: as informações registradas em algum suporte, como livros, relatórios, periódicos, jornais, entre outros. O segundo: as informações não registradas, ou seja, informações que não possuem registros formalizados em um determinado suporte, em virtude da dinamicidade do ambiente e do esporte, ou até mesmo pela ausência de percepção dos próprios produtores quanto ao valor da informação nesse segmento.

Observando os tipos informacionais mencionadas por Valentim (2006), é possível observar que elas são segmentadas de acordo com o contexto de produção e uso. Em relação ao ambiente esportivo, isso também ocorre.

No contexto esportivo, podemos separar dois ambientes: o interno e o externo. O ambiente interno é dividido em duas áreas: a área técnica, composta por 
atletas, treinadores e demais membros que estão diretamente relacionados com a área afim, ou seja, a prática esportiva; e a área administrativa, responsável por realizar processos administrativos que propiciam suporte à área técnica. A área administrativa diz respeito aos processos responsáveis por elaborar, gerir e processar contratos, publicidade e propaganda, assuntos financeiros, entre outros processos necessários para que as atividades desenvolvidas pela área técnica sejam realizadas, independente da modalidade esportiva.

Evidencia-se, também, que a informação está presente em três níveis organizacionais: estratégico, tático e operacional. No nível operacional, encontramse os sujeitos organizacionais envolvidos de maneira direta ou indireta com os treinamentos, competições e atividades que proporcionam sustentação para o desenvolvimento da área afim do esporte em questão. O nível tático, também denominado como nível intermediário, é responsável por intermediar e processar informações entre os níveis operacional e estratégico, além de responsável pela coordenação e gestão de informações relacionadas às atividades e tarefas deste nível. No âmbito do nível estratégico, situam-se os indivíduos responsáveis por analisar informações para projeções futuras, a relação da entidade esportiva ou do atleta com os torcedores/fãs, entre outros processos.

\section{TIPOLOGIA DA INFORMAÇÃO ESPORTIVA}

Com base na delimitação dos ambientes e níveis em que as informações se encontram, é possível definir seus tipos e fontes. A tipologia informacional aplicada agrupa e classifica as informações em dois contextos: formal e informal.

São consideradas informações formais aquelas disponibilizadas, de maneira estruturada, em revistas especializadas, teses, dissertações, artigos, jornais, anais de eventos, entre outros. As informações informais não são estruturadas, normalmente ocorrem a partir de contatos pessoais e telefônicos, conversas com fornecedores, clientes e demais processos nos quais inexiste a possibilidade de registro (Quadro 1). 
Quadro 1 - Sistematização: tipologia, tipo de informação, fonte e ambiente.

\begin{tabular}{|l|l|l|c|}
\hline Tipologia & Informação & \multicolumn{1}{|c|}{ Fonte } & Ambiente \\
\hline Formal & Médica & Área Técnica & Interno \\
\hline Formal & Física & Área Técnica & Interno \\
\hline Formal & Atletas (treinos e competições) & Área Técnica & Interno \\
\hline Formal & Financeira & Área Administrativa & Interno \\
\hline Formal & $\begin{array}{l}\text { Administrativa (contratos de atletas, } \\
\text { patrocínio) }\end{array}$ & Área Administrativa & Interno \\
\hline Formal & Marketing & Área Administrativa & Interno \\
\hline Formal & Sócios & Área Administrativa & Interno \\
\hline Formal & Atletas observados & $\begin{array}{l}\text { Internet, TV, } \\
\text { empresários, entre } \\
\text { outros. }\end{array}$ & Externo \\
\hline Informal & Torcedores & $\begin{array}{l}\text { Internet (redes sociais), } \\
\text { TV, institutos de } \\
\text { pesquisa, entre outros. }\end{array}$ & Externo \\
\hline Informal & Partida & Área Técnica & Externo \\
\hline Informal & $\begin{array}{l}\text { Mercado de investimentos (Especulação de } \\
\text { atletas e patrocínio) }\end{array}$ & $\begin{array}{l}\text { Empresários, jornais, } \\
\text { internet entre outras } \\
\text { fontes. }\end{array}$ & Externo \\
\hline Informal & Partida (Jogadas para analise dos árbitros) & Partida em andamento & Externo \\
\hline Informal & $\begin{array}{l}\text { Informações não mapeadas (Em processo de } \\
\text { transformação) }\end{array}$ & $\begin{array}{l}\text { Várias (Indefinidas) } \\
\text { Externo/ } \\
\text { Interno }\end{array}$ \\
\hline
\end{tabular}

Fonte: Elaboração própria.

O conceito de informação esportiva é diretamente relacionado ao ambiente e estrutura de organizações esportivas, ou seja, a informação pode ser compreendida, apropriada e usada de acordo com o sujeito organizacional que com ela está interagindo. Exemplo disso é a visão do atleta em relação a uma determinada informação, qualificando-a de relevante ou não, diferentemente de um dirigente de um clube que pode interagir de maneira distinta com a mesma informação, uma vez que suas necessidades e interesses são outros. Nessa perspectiva, é importante perceber as potencialidades de um tipo de informação, cujo valor atribuído é distinto para cada nível e/ou sujeito organizacional.

Ressalta-se que existe um número ilimitado de informações informais no ambiente externo, trafegando em fluxos informais que, por sua vez, podem se transformar em informações formais na interação com os distintos sujeitos organizacionais. De acordo com suas necessidades/demandas, as informações de distintas fontes e ambientes podem se inter-relacionar transformando-se em novos dados e informações, fator que possibilita a geração de conhecimento. 
Figura 1 - Informação formal e informal e a geração de nova informação/conhecimento.

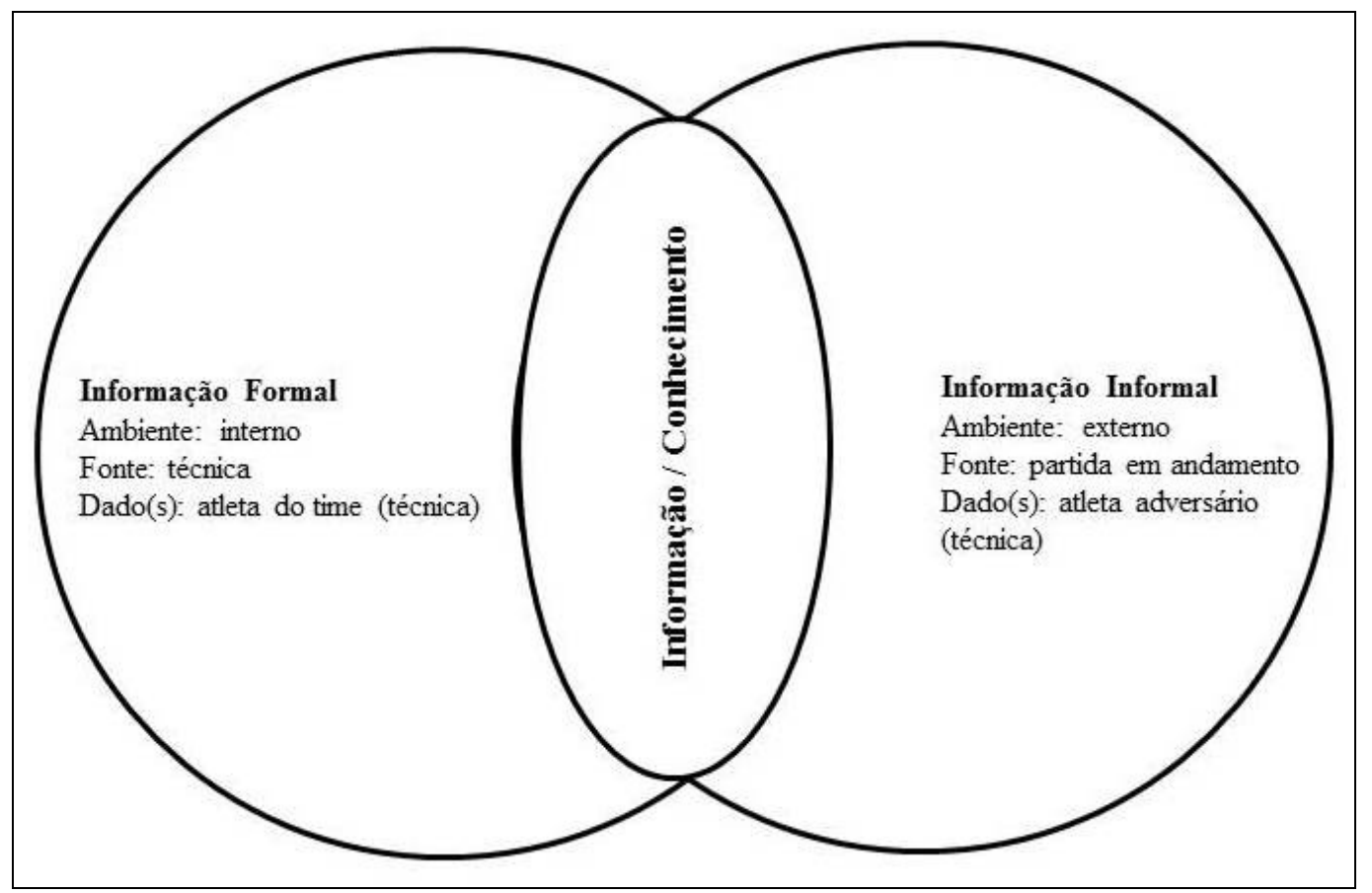

Fonte: Elaboração própria.

A informação esportiva relacionada ao futebol deve ser direcionada às necessidades e demandas de seu público: informações situacionais sobre o jogo, visando escolher a melhor opção tática; histórico do atleta; dados estatísticos relativos às partidas anteriormente realizadas etc. Sendo assim, há a junção da informação formal, cuja fonte é a área técnica do ambiente interno que, por sua vez, podem ser transformadas em insumo para a geração de conhecimento, a partir da percepção e apropriação de um sujeito organizacional. Isso possibilita a geração de conhecimento individual que pode ser compartilhado no ambiente organizacional (Figura 1).

\section{A INFORMAÇÃO ESPORTIVA COMO DIFERENCIAL COMPETITIVO}

Monteiro, Botelho e Valls (2009), corroborando com Clarke (2000), sistematizaram as informações registradas (formais) de cunho esportivo. As autoras estabeleceram uma relação entre os tipos de informações, as motivações e finalidades e as fontes utilizados com os usuários (Quadro 2). 
Quadro 2 - Usuários da informação esportiva e suas necessidades.

\begin{tabular}{|c|c|c|c|}
\hline Usuários & $\begin{array}{c}\text { Tipos de } \\
\text { Informação }\end{array}$ & $\begin{array}{l}\text { Motivação/ } \\
\text { Finalidades }\end{array}$ & Fontes \\
\hline $\begin{array}{l}\text { Gestores } \\
\text { Desportivos }\end{array}$ & $\begin{array}{l}\text { - Administrativas; } \\
\text { - Políticas; } \\
\text { - Legislação. }\end{array}$ & $\begin{array}{l}\text { Definição de políticas e } \\
\text { estratégias } \\
\text { administrativas. }\end{array}$ & $\begin{array}{l}\text { Atualidade política, } \\
\text { diretórios, relatórios, } \\
\text { informações } \\
\text { estatísticas, legislação } \\
\text { e gestão. }\end{array}$ \\
\hline $\begin{array}{l}\text { Especialistas e } \\
\text { Pesquisadores }\end{array}$ & - Científica. & $\begin{array}{l}\text { Pesquisa científica e } \\
\text { atuação de especialistas } \\
\text { (médicos, psicólogos, } \\
\text { sociólogos, } \\
\text { fisioterapeutas). }\end{array}$ & $\begin{array}{l}\text { Obras especializadas, } \\
\text { atas de congressos e } \\
\text { periódicos, bases de } \\
\text { dados bibliográficos. }\end{array}$ \\
\hline $\begin{array}{l}\text { Treinadores, } \\
\text { Atletas e } \\
\text { Árbitros }\end{array}$ & $\begin{array}{l}\text { - Fundamentos dos } \\
\text { esportes; } \\
\text { - Técnicas e táticas; } \\
\text { - Estatísticas } \\
\text { (resultados de } \\
\text { competições, } \\
\text { classificações); } \\
\text { - Normas e regras. }\end{array}$ & Aprendizado e atuação. & $\begin{array}{l}\text { - Obras didáticas, } \\
\text { periódicos e jornais } \\
\text { especializados, } \\
\text { material audiovisual; } \\
\text { - Normas. }\end{array}$ \\
\hline $\begin{array}{l}\text { Órgãos de } \\
\text { Comunicação } \\
\text { Social }\end{array}$ & $\begin{array}{l}\text { - Históricas; } \\
\text { - Atualidades. }\end{array}$ & $\begin{array}{l}\text { Reportagens e coberturas } \\
\text { de eventos esportivos. }\end{array}$ & $\begin{array}{l}\text { - Agências fotográficas } \\
\text { e de notícias. }\end{array}$ \\
\hline $\begin{array}{l}\text { Público em } \\
\text { Geral }\end{array}$ & $\begin{array}{l}\text { - Biografias de atletas e } \\
\text { resultados de } \\
\text { competições. }\end{array}$ & Interesse pelos esportes. & $\begin{array}{l}\text { Órgãos de } \\
\text { comunicação social, } \\
\text { periódicos e } \\
\text { organizações } \\
\text { especializadas. }\end{array}$ \\
\hline
\end{tabular}

Fonte: Botelho, Monteiro e Valls (2007, p. 177).

$\mathrm{Na}$ sistematização supracitada foram consideradas apenas as informações formais, ou seja, registradas em algum tipo de suporte. No entanto, no ambiente esportivo existem várias informações que não são registradas, cuja importância muitas vezes não é percebida pelos usuários e isso ocorre por distintos fatores, entre eles pode-se citar: a falta de estrutura que impossibilita aplicar um modelo de gestão de informação que, por sua vez, dificulta a prospecção e o monitoramento, bem como a percepção da importância de seu uso nesse cenário.

Prospectar, monitorar e filtrar informação é uma atividade complexa, porquanto as informações estão relacionadas a mais de um contexto, isto é, a informação pode estar contida em distintos ambientes e níveis hierárquicos, conforme mencionado anteriormente. O ambiente interno produz informação a partir da ação dos sujeitos organizacionais (processos, atividades e tarefas). As informações geradas no ambiente externo à organização advêm da ação de diferentes stakeholders, sendo que muitas vezes são responsáveis por interferir nos processos internos da organização. 
Evidencia-se que os dados se constituem no ponto de partida para a geração de informações esportivas. As informações ganham atributos devido aos diferentes níveis de contexto, análises e necessidades dos usuários, conforme explica Valentim (2002, p. 3), para que: “[...] um dado seja considerado informação, necessariamente requer algum tipo de análise, exige um consenso da área quanto aos termos adotados em relação ao seu significado e, finalizando, deve estar em sintonia com o público a que se destina."

A informação esportiva está contida no ambiente esportivo como um todo que, ao se relacionar com um determinado sujeito organizacional deste segmento pode ser transformada em insumo para a tomada de decisão.

Belluzzo (2009) relaciona a importância do uso da informação esportiva por seus usuários, com o intuito de gerar conhecimento para uma determinada aplicação, ou seja, corrobora a importância da relação do usuário com o ambiente informacional de modo que possa transformar a informação em conhecimento. Nessa perspectiva,

[...] a área de abrangência do esporte deve estar posicionada como uma matriz claramente social e centrada no estudo das propriedades gerais da informação (objeto/fenômeno) e na análise dos processos em que ela se transforma em conhecimento. Compete aos interagentes desse fluxo desenvolver ações, tais como: analisar as atividades informacionais, os atores envolvidos, a organização onde estão inseridos e a dinâmica do contexto de forma sistêmica, indo além da própria informação produzida - envolver sua representação nos fatores internos e externos na modelação da informação produzida, revelando-se a sua integração sócio-cultural e a intencionalidade/evidencia que se acha subjacente, quer pelo conteúdo, quer pela estrutura ou forma atribuída ou mesmo pelo próprio fluxo informacional, visando a garantia de que a informação poderá contribuir à construção do conhecimento, desde que: seja acessível, autêntica, íntegra, fidedigna, inteligível e utilizável em todo o processo que compreende o comportamento informacional, do que é indissociável a propriedade e suas correlações com as atuais necessidades informacionais dos usuários/ produtores na sociedade contemporânea (BELLUZZO, 2009, p. 11).

A mesma autora também ressalta que a relação entre a informação esportiva e seus usuários é cíclica, pois da mesma maneira que o usuário a capta no ambiente esportivo pode transformá-la em conhecimento. Da mesma maneira, esse 'novo' conhecimento gerado por um sujeito organizacional pode ser reproduzido a partir de seu registro, ou seja, transforma-se em informação. Tal processo permite 
que o conhecimento seja acessível, fidedigno e de fácil uso.

Ressalta-se que não somente as informações registradas são utilizadas pelos usuários da informação esportiva, porquanto as informações produzidas e repassadas ao ambiente esportivo, muitas vezes não são registradas em nenhum tipo de suporte, evidenciando que o fluxo informal está presente nesse tipo de organização.

No que tange aos fluxos informais, as organizações esportivas e seus usuários utilizam de modo constante as informações que nele trafegam. Como exemplo, é possível destacar o treinador que, no decorrer de uma partida, elabora e reelabora o próprio conhecimento, redefinindo estratégias táticas de ação, ou os atletas que ao realizarem suas ações ao longo da partida, observam os adversários e elaboram e reelaboram o próprio conhecimento, modificando suas ações dentro do campo.

No contexto esportivo, por sua complexidade, há também a desinformação ou a contrainformação. Para se compreender o significado de desinformação é fundamental rever alguns aspectos teóricos da informação no contexto da comunicação e do esporte. Dessa maneira, é lícito tratar a informação como dados emitidos por meio de mensagem:

A informação não é a mensagem, não são os dados. A informação é uma resultante da interpretação dos dados. Deve se levar em conta esse fenômeno, pois, muitas vezes, uma mensagem é enviada com dados corretos, mas a interpretação é feita de maneira incorreta. Neste caso não se tem a informação, mas um erro (SIMÕES, 2009, p. 19).

Ao se analisar o conceito de informação descrito por Simões (2009), observase que este autor estabelece uma conexão entre dados, mensagem e interpretação do usuário, cujas variáveis são essenciais para a transformação da informação em conhecimento. Desse modo, as informações no contexto esportivo podem ser utilizadas, tanto para informar quanto para desinformar. $O$ processo de desinformação ocorre de maneira intencional, pois segundo Simões (2009), entende-se por desinformação

[...] o processo de envio intencional de mensagens contento dados errados ou falsos. Esses dados, depois de organizados, analisados e tomados como verdadeiros, levam aquele que receber as 
mensagens a tomar decisões erradas, que irão prejudicar seus objetivos (SIMÕES, 2009, p.24).

A desinformação ocorre em todos os níveis do contexto esportivo. No âmbito do futebol pode-se exemplificar esse tipo de situação, quando um jogador ao driblar seu adversário com a bola, simula um lado e segue por outro, ou seja, de uma maneira informal está realizando a desinformação, já que o atleta está enviando uma mensagem que não é verdadeira, visando exatamente causar uma desinformação no adversário. Existem inúmeros processos de desinformação que ocorrem durante uma partida como, por exemplo, o atleta simular uma falta ou até mesmo simular uma agressão por parte do adversário, enviando mensagens não verdadeiras ao árbitro, com a finalidade de prejudicar o adversário. Esses exemplos evidenciam o uso intencional da desinformação no âmbito do esporte.

O processo de desinformação também pode ser encontrado no nível estratégico dos clubes de futebol como exemplo, destacam-se as informações divulgadas ao mercado pelos dirigentes sobre os atletas, com a finalidade de aumentar a especulação sobre uma possível aquisição ou venda. Nesse processo, um clube de futebol que deseja vender um atleta envia informações sobre 0 rendimento em treinamentos que, muitas vezes, não condizem com a verdade.

Observa-se que ao emitir uma informação não fidedigna de maneira intencional, o emissor espera, obviamente, de alguma maneira, obter alguma vantagem. Destaca-se que a emissão intencional de uma informação inverídica pode gerar situações complicadas como, por exemplo: quando um clube deseja adquirir um determinado atleta, a agremiação dissemina de maneira intencional, por meio de empresários e parceiros, informações que prejudiquem o atleta em questão e, assim, pode ocorrer à desvalorização no que tange ao valor financeiro do atleta, fazendo com que o clube o compre por um valor mais baixo; quando um árbitro aplica uma penalidade, a partir de uma desinformação e, assim, prejudica a classificação de um time de futebol em um campeonato. Exemplos como esses evidenciam que é recorrente no ambiente esportivo futebolístico o processo de desinformação.

A desinformação é um processo muito difícil de ser identificado, principalmente no ambiente esportivo, pois ela ocorre a partir de determinadas ações em que o indivíduo que está interagindo com o emissor das informações 
necessita tomar uma decisão.

Além disso, existem as informações que são plantadas e/ou cogitadas no mundo esportivo que, muitas vezes, podem se transformar em especulações, pois são informações falsas disseminadas no ambiente, ou seja, contrainformação. Dessa maneira, as informações verdadeiras se misturam às informações falsas, confundindo os sujeitos organizacionais responsáveis por tomar decisões.

Um dos fatores que contribuem para que a desinformação/contrainformação seja profícua no ambiente esportivo, é o fato de que muitas informações trafegam em fluxos informais. A propagação da informação no mundo esportivo, ganha força e velocidade, já que o ambiente em que esta informação trafega, por conta da própria cultura, ignora a fidedignidade da fonte primária. Os indivíduos responsáveis por disseminar a informação, muitas vezes, são utilizados apenas como transmissores e, em grande parte desses processos, são enganados por suas próprias fontes de informação.

\section{INFORMAÇÃO ESPORTIVA NO CONTEXTO DOS CLUBES DE FUTEBOL}

A informação pode gerar diversas vantagens às organizações esportivas. Os autores Davenport e Harris (2007) mencionam esportes como o beisebol, o basquete e o futebol, entre outros, que fazem uso da informação visando obter vantagem competitiva.

No âmbito técnico, a estatística é frequentemente utilizada no basquete e no beisebol gerando dados e informações que, posteriormente, serão alvo da análise visando gerar inteligência buscando a melhoria do esporte e, cujo êxito, ocorre devido ao alinhamento das informações à percepção e à criatividade de quem faz uso das informações.

O técnico do St. Louis Cardinals, Tony La Russa (cujo time venceu o World Series em 2006), um dos melhores treinadores de beisebol, combina de forma brilhante a inteligência analítica e a intuição para decidir quando contratar uma personalidade contagiante para alavancar o moral da equipe (DAVENPORT; HARRIS, 2007, p. 22).

O uso da informação no esporte é evidenciado no futebol americano pelo New England Patriots que, emprega as informações quase de maneira plena, abordando 
a área administrativa, técnica e mercadológica, analisando a satisfação dos torcedores. O futebol americano é considerado um dos esportes mais lucrativos do mundo. A informação nesse contexto propicia o apoio à tomada de decisão desde o nível técnico até o estratégico, proporcionando êxito às competições esportivas.

O New England Patriots, por exemplo, tem demonstrado um desempenho particularmente bem-sucedido, com a vitória recente de três Super Bowls ${ }^{1}$ em quatro anos. O time faz uso extensivo de dados e modelos analíticos, tanto em campo quanto fora dele. Profundas análises ajudaram o time a selecionar seus jogadores e ainda permanecer abaixo do teto salarial (no ano passado, a média salarial do time ficou no vigésimo quarto lugar na National Football League $^{2}$ ). O time seleciona jogadores sem utilizar os serviços de olheiros empregados por outros times e classifica as seleções potenciais com base em fatores não tradicionais, como inteligência e disposição de usar o ego pessoal em beneficio da equipe (DAVENPORT; HARRIS, 2007, p. 22-23).

A utilização da informação no âmbito técnico também faz parte do modo com que a equipe do New England Patriots trabalha, demonstrando que o uso das informações pode projetar situações e antever a estratégia dos adversários.

[...] fazem a utilização extensiva da inteligência analítica para decisões em campo. Eles empregam estatísticas para decidir se tentam fazer um ou dois pontos depois de um touchdown ou se desafiam a decisão do juiz, por exemplo. Tanto seus técnicos quanto os jogadores são reconhecidos por seu extensivo estudo de filmagem de jogos e estatística, e o treinador chefe, Bill Belichick, é famoso por ler compenetradamente artigos de economistas acadêmicos sobre probabilidades estatísticas de resultado do futebol americano (DAVENPORT; HARRIS, 2007, p. 23).

O uso da informação como insumo para a melhoria mercadológica é

\footnotetext{
${ }^{1}$ Super Bowl é um jogo do campeonato da National Football League (NFL) estadunidense que decide o campeão da temporada do ano anterior. Disputada desde 1967, a partir da junção das duas principais ligas do desporto no país (NFC e AFC), é o maior evento desportivo e a maior audiência televisiva do país, assistido anualmente por milhões de pessoas nos Estados Unidos e em todo o mundo. É também um evento que apresenta a publicidade mais cara da televisão, pois patrocinadores desembolsam pequenas fortunas para exibirem suas propagandas no intervalo. Disponível em: <http://pt.wikipedia.org/wiki/Super_Bowl>. Acesso em: 22 jul. 2012.

${ }^{2}$ A National Football League (NFL) é a maior liga de futebol americano do mundo, com trinta e dois times nos Estados Unidos. Em termos de renda e número de fãs, a NFL é a maior liga de esportes na América do Norte. O valor médio dos clubes avaliado em 2008 é de 1,04 bilhão de dólares, sendo o mais valioso o Dallas Cowboys, que chega a valer 1,612 bilhão de dólares. A divisão mais valiosa da NFL é a NFC Leste, formada por Cowboys, Washington Redskins, New York Giants e Philadelphia Eagles, todos valendo mais de um bilhão de dólares. Disponível em: <http://pt.wikipedia.org/wiki/National_Football_League>. Acesso em: 22 jul. 2012.
} 
evidenciado, quando a equipe utiliza os resultados colhidos para melhoria constante do negócio esportivo. Passando a atender de maneira eficiente o principal cliente, qual seja, o torcedor, bem como possibilitando a realização de mudanças estratégicas, usando como base a opinião desses mesmos clientes.

Fora de campo, o time utiliza análises detalhadas para avaliar e melhorar a "experiência total dos fãs". Em cada jogo em casa, por exemplo, entre 20 e 35 pessoas recebem a tarefa específica de criar indicadores quantitativos para a comida, o estacionamento, 0 pessoal, a limpeza dos banheiros, entre outros fatores. Os fornecedores externos de serviços são monitorados, para renovação de contratos e recebem incentivos para melhorar seu desempenho (DAVENPORT; HARRIS, 2007, p. 23).

Ao se observar o aproveitamento da informação no ambiente esportivo, evidencia-se que esta se aproxima da informação empresarial. Um ambiente esportivo ou uma organização esportiva possui distintas informações: financeiras, de mercado, e demais informações encontradas em empresas, possuindo particularidades decorrentes do contexto esportivo.

O que difere, de maneira mais contundente, uma organização esportiva de uma organização tradicional reside na dinamicidade e rapidez em que o ambiente técnico está inserido, tendo em vista que sua 'produção' ocorre em um ambiente de difícil controle como, por exemplo, as partidas e competições. Nesse contexto, a informação passa a ser essencial para reduzir as incertezas no momento da tomada de decisão.

Dessa maneira, entende-se por informação esportiva qualquer informação que tenha origem no ambiente esportivo, sendo gerada no contexto administrativo ou da prática do esporte, cuja finalidade é diretamente voltada ao esporte. Nesse caso, a informação esportiva futebolística é compreendida como aquela informação originária do esporte 'futebol', que pode ter origem nos processos técnicos, ou seja, das atividades desenvolvidas pelos atletas, treinador e demais membros da comissão técnica ou áreas de apoio, bem como podem ter origem administrativa, como, por exemplo, informações financeiras, contratos e demais informações relacionadas ao esporte futebol. As informações externas que interagem com o contexto do futebol também se encaixam e ganham o status de informação futebolística.

As informações esportivas estão totalmente relacionadas ao esporte no qual 
trafegam. Nessa ordem de considerações, as informações passam a ter várias dimensões, quer seja em relação à dimensão dos atletas, dos árbitros, dos torcedores, quer seja das entidades esportivas, enfim, todas as dimensões que se relacionam de maneira direta com o esporte. A contextualização do esporte é o primeiro delimitador para que a informação ganhe a qualificação 'esportiva', afinal as informações, bem como as necessidades dos usuários e seus usos, variam de acordo com o esporte.

Tendo o esporte futebol como delimitador, observa-se que a informação esportiva ganha uma nova subdivisão, a 'informação futebolística'. À luz disso, a informação esportiva ganha o futebol como complemento para que se torne possível uma maior delimitação e foco no contexto da informação. Segundo Simões (2009), o futebol tem como objetivo central o gol no jogo. Por tal motivo, vencer a partida, fazendo mais gols que o adversário, é o objetivo da equipe.

No domínio do futebol, observam-se vários atores que se relacionam entre si, bem como entre as instituições em que atuam. Como exemplo, pode-se mencionar o jogador que no nível informacional pode ser tratado de maneira individual (o atleta em si), entretanto, também pode ser tratado de maneira coletiva (representa e defende um clube de futebol).

\begin{abstract}
Para vencer seu adversário, um time deve obter com presteza mais informações que seu rival. Deve saber escolher, entre as alternativas que possui, suas probabilidade e agir com o máximo de velocidade. O termo probabilidade refere-se, também, à teoria da informação. $O$ jogo de futebol caracteriza-se pela maior ou menor escolha de alternativas que cada jogador é capaz de obter por meio da informação. Compare-se a atuação de uma equipe altamente qualificada com outra com baixo teor de técnica, velocidade, motivação (SIMÕES, 2009, p.26).
\end{abstract}

Analisando um clube de futebol é possível visualizar que este tipo de organização possui em sua estrutura todos os níveis internos, que se relacionam de maneira constante com o ambiente externo. Internamente um clube de futebol possui em sua estrutura desde o nível operacional, do qual podemos destacar os jogadores, a comissão técnica e os demais membros que se relacionam de maneira direta com as partidas de futebol, até o nível estratégico que é composto por seus dirigentes.

Nessa perspectiva, o nível operacional compreende os atletas, o técnico, a 
comissão técnica e os demais membros que se relacionam de maneira constante com as partidas e treinamentos. Pode-se considerar o treinador o maestro da equipe, aquele que detém a responsabilidade de agregar todos os que atuam nesse nível.

Entre as atividades que o técnico realiza, Simões (2009, p. 31) destaca que o treinador, mesmo de maneira não estruturada, passa o tempo todo prospectando e filtrando informações e organizando-as com a finalidade de formar uma equipe que atenda dois princípios-chave: 1) pensando na equipe organizada isoladamente; e 2) em razão de cada adversário que irá enfrentar.

Dessa maneira, o treinador é responsável por organizar todo o conjunto de jogadores que vão a campo, seus reservas, e demais componentes que residem em torno desses processos. Pode-se afirmar que o trabalho do técnico é:

[...] reduzir incertezas, as dúvidas, no seu time e criar o maior número de incertezas no time adversário. Faz isso, "escondendo o jogo", treinando secretamente, criando novas táticas, alterando as posições dos jogadores, alterando posições. Tudo que o técnico faz está relacionado com a informação obtida e as decisões tomadas em razão de suas vivências e conhecimentos (SIMÕES, 2009, p.31).

O treinador é uma figura importante dentro de um clube de futebol, afinal, é por meio dele que todas as peças se inter-relacionam de maneira que, quando isso não ocorre, ele é o primeiro a ser penalizado. Sendo assim, evidencia-se a importância da informação esportiva para o treinador no âmbito de um clube de futebol.

Sem dúvida outro personagem importantíssimo nesse contexto são os jogadores. Os atletas são responsáveis por colocar em prática a estratégia tática desenvolvida pelo treinador. Simões $(2009$, p. 36) ressalta quatro habilidades básicas que os atletas devem ter:

1) Condições físicas: correr, saltar, cabecear, dar saltos mortais. Em outras palavras, condições atléticas em diversas atividades físicas;

2) Ter hábil domínio da bola, no chão e no ar;

3) Possuir equilíbrio emocional, levando-o à tranquilidade, dentro e fora de campo;

4) Rapidez e qualidade neurológica.

É considerado jogador de talento aquele que possui todas as habilidades 
supracitadas, sobretudo, com ênfase na característica quatro, a saber: no que se refere à rapidez e qualidade neurológica. Tal característica concede ao atleta a possibilidade de realizar jogadas e ir além, antecipar jogadas etc.

Essas competências e habilidades são relacionadas a dados e informações, uma vez que o atleta que compreender, se apropriar e usar dados e informação para adquirir essas competências e habilidades possuirá um diferencial competitivo.

Destacando o processo de gestão da informação, os atletas buscam informações e as analisam, tomando assim as melhores decisões. As informações geralmente não são obtidas na partida de futebol que está em andamento, ao contrário, em muitos casos, os atletas buscam informações dos adversários em jogos anteriores como, por exemplo, analisando um vídeo, e outras informações disseminadas pela comissão técnica.

Os atletas com essas características são responsáveis por ações estratégicas no contexto das partidas. Eles, igualmente, são responsáveis por jogadas que resultam em gols e, consequentemente, em vitórias às suas equipes. Com frequência, os atletas que possuem competências analíticas, são aqueles que conseguem fazer uso do que é disseminado pelo treinador e demais membros da comissão técnica, haja vista que detém visão privilegiada dos fatos instantâneos que ocorrem no jogo, bem como dos fatos e acontecimentos de partidas anteriores realizadas.

Outros sujeitos que compõem o âmbito operacional, como o preparador físico, preparador de goleiro e auxiliar técnico, fazem uso das informações geradas durante os treinos e partidas, a fim de tomar decisões no âmbito dos treinamentos de suas áreas. Existem também o médico, fisioterapeuta, massagista e demais pessoas responsáveis por dar suporte aos treinadores e atletas. Esses profissionais analisam situações individuais, cujas informações são mencionadas pelos próprios atletas e, também, tomam decisões consultando inúmeras fontes de informações específicas de suas áreas de atuações.

Todas as atividades realizadas nesse âmbito geram informações que, por sua vez, podem gerar conhecimento, mesmo que de maneira não estruturada. São conhecimentos fundamentais para as organizações esportivas, porque se constituem no coração de qualquer clube de futebol, pois se trata da área responsável pela existência dessas organizações esportivas.

A área tática ou intermediária de um clube de futebol é composta de gestores, 
coordenadores e demais membros, responsáveis por realizar a intermediação dos objetivos e metas estabelecidos pela área estratégica junto às atividades desempenhadas pelo nível operacional. Observa-se que a maior parte da informação formal (documentos) de um clube de futebol reside neste nível organizacional. Como exemplo, destacam-se os documentos financeiros, fiscais, contratos de atletas e demais suportes responsáveis por registrar as informações que trafegam formalmente nos clubes de futebol.

As informações financeiras se constituem em notas fiscais de entrada e saída, talonários de venda de ingressos, informações sobre a folha de pagamento de atletas, comissão técnica e demais funcionários do clube, entre outras. As informações financeiras estão contidas em vários tipos de suportes: impressos, eletrônicos, digitais. Esse nível também é responsável pela gestão administrativa do clube de futebol como, por exemplo, a elaboração de contratos, termos, propostas, e demais atividades relacionadas ao futebol no âmbito administrativo.

Além das informações mencionadas, é neste nível organizacional que se encontra a área de marketing e comunicação, responsável por divulgar os atletas e o clube. É a área responsável por realizar as comunicações do clube com o ambiente interno e externo. Os responsáveis pelos processos de marketing de um clube de futebol procuram, por meio das comunicações, evidenciar as informações do clube, cuja finalidade é a valorização da imagem e marca institucional e, como consequência deste trabalho, pode obter mais recursos financeiros para o clube.

Outro processo realizado por essa área refere-se ao relacionamento entre o clube (seus atletas, comissão técnica e diretoria) com os torcedores, tendo como objetivo a manutenção dos torcedores atuais e a captação de novos torcedores, o que também resulta em um aumento de receita financeira para o clube. Atualmente, esse processo também ocorre por meio da utilização das redes sociais virtuais e demais mecanismos de massa. Levando-se isso em conta, pode-se afirmar que esse setor é responsável por divulgar/disseminar todas as informações do clube. Além de externalizar a informação, o setor busca e analisa informações dos torcedores no ambiente externo, com a intenção de desenvolver e promover produtos e serviços da organização esportiva voltados ao público torcedor. Esse processo normalmente é realizado nas mesmas fontes em que o clube divulga/dissemina suas informações.

Dessa maneira, o nível tático organizacional é essencial para o contexto 
informacional do clube, pois é ela que busca fontes de informação para os níveis operacional e estratégico, analisa e transforma dados em informações para ambos os níveis.

A informação no nível estratégico de um clube de futebol é em grande parte utilizada para subsidiar a tomada de decisão. Os diretores dessas organizações utilizam informações de fontes internas e externas para subsidiar as tomadas de decisão. As decisões são tomadas com diferentes finalidades, desde a contratação ou dispensa de um jogador até a vinculação do clube a um possível patrocínio. Um exemplo disso é a contratação de um novo atleta, os diretores precisam observar vários vídeos do jogador, o comportamento do atleta durante as partidas, ou seja, analisar as informações técnicas, físicas e comportamentais do atleta. Este tipo de informação, geralmente, é concedido por empresários. No entanto, é importante que os diretores tenham acesso a informações estatísticas do atleta como, por exemplo, o seu aproveitamento em fundamentos, gols realizados, entre outras informações, sendo que as fontes dessas informações são sites, jornais e revistas especializados em esporte futebolístico. É importante ressaltar, que atualmente algumas empresas estão se especializando nesse tipo de serviço, fornecendo informações aos clubes de futebol e às emissoras de TV.

Os dirigentes também necessitam buscar informações do atleta no âmbito médico, analisam o histórico de contusões e recuperações de eventuais problemas. Normalmente, as fontes de informações são os médicos dos clubes em que o atleta atuou ou até mesmo notícias de distintas mídias. Outra informação bastante relevante refere-se à disciplina do atleta, assim, buscam informações sobre o comportamento e o relacionamento do jogador com outros jogadores de antigas equipes que, por sua vez, se tornam fontes desse tipo de informação.

Por último, os dirigentes, necessitam de informação financeira em que analisam o valor que se pretende investir, ou seja, qual é o custo-benefício do atleta para o clube, de modo a tomarem a decisão a mais assertiva possível. 
Figura 2 - Tomada de decisão: análise e contratação de um jogador.

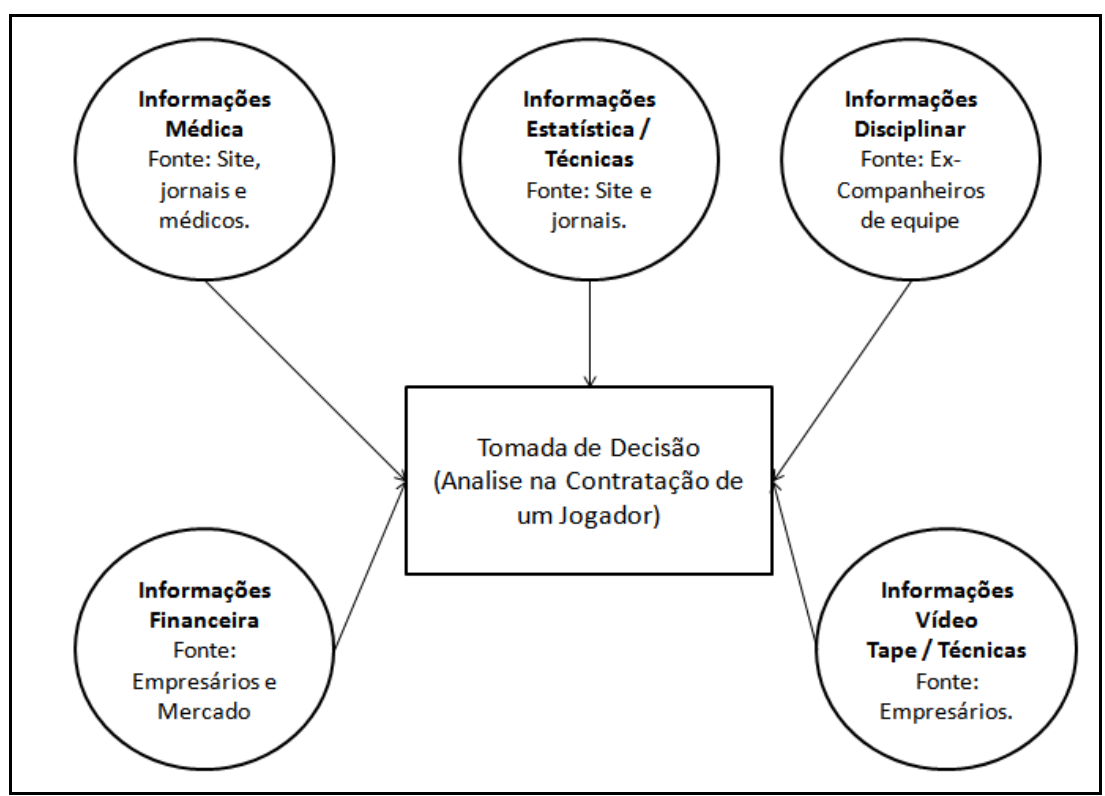

Fonte: Elaboração própria.

As informações descritas na Figura 2 normalmente se constituem a partir da fusão de diversas fontes, suportes e mídias. Os sujeitos organizacionais do nível tático realizam as fusões e transformações dos dados em informações, com a finalidade de atender as necessidades específicas de cada nível organizacional.

Existem vários outros processos em que a cúpula estratégica de uma organização esportiva necessita para que a tomada de decisão se torne mais assertiva, o que demonstra a importância do uso da informação nas atividades desenvolvidas pelos sujeitos organizacionais que compõem esse nível nos clubes de futebol. O uso, bem como a falta de uso de informações para desenvolver as atividades, pode trazer consequências positivas ou negativas para essas organizações, um exemplo negativo é a perda de recursos, desde financeiros até humanos, o uso de informações propicia a redução de incerteza e mais consistência na formulação de cenários futuros.

Da mesma maneira que os dirigentes buscam informações no ambiente externo, os torcedores e investidores buscam informações internas geradas nos clubes. Os torcedores são consumidores das informações projetadas pelos clubes. Prova disso, são as relações dos clubes com os torcedores, por meio das redes sociais que são cada vez mais consolidadas.

Disseminar informações ao ambiente externo é uma estratégia para aproximar os clubes dos torcedores, aprofundando a relação do torcedor com o 
clube e seus atletas, isto é, ao disponibilizarem informações principalmente na Internet e nas redes sociais, propiciam uma maior interação entre o clube e os torcedores.

No contexto dos investidores as informações disseminadas pelos clubes ao ambiente externo são estratégicas, uma vez que disponibilizam informações sobre os atletas, a torcida e os produtos, demonstrando a real possibilidade de retorno aos investidores. Essa estratégia de divulgação/disseminação de informações ao ambiente externo tem como finalidade o fortalecimento da imagem e da marca do clube, pois mesmo sendo um valor intangível é o que sustenta muitos clubes de futebol.

Os fluxos informacionais nos clubes de futebol merecem uma atenção especial, levando-se em conta que por eles trafegam um número ilimitado de informações. Destaca-se, no entanto, que o ambiente em que os clubes estão inseridos é constituído por muita especulação, principalmente no mercado de transações de atletas. Esse tipo de informação, em geral, transita em fluxos informais como, por exemplo, em conversas de bastidores, nas quais nem sempre a fonte é acessível e/ou fidedigna. Muitas vezes os clubes e os empresários realizam o processo de desinformação, conforme anteriormente mencionado, o que dificulta a confiabilidade da informação; todavia, desprezar uma informação, mesmo correndo o risco de ser uma informação falsa, pode fazer com que o clube perca oportunidades no dinâmico mercado do futebol.

Outros tipos de informações que trafegam no fluxo informal são as informações referentes à área técnica, pois existe um número incalculável de informações que pertencem e fazem parte da área técnica. Em sua maioria, são informações que são disseminadas, apropriadas, utilizadas e transformadas em conhecimento, por se tratar de informações não registradas em nenhum suporte é complexa sua transmissão, porquanto é intrínseca aos indivíduos dessa área.

Muitas informações que circulam nos clubes de futebol referem-se aos fluxos informais devido à dinamicidade do ambiente em que estão inseridas e a dificuldade de registrar as informações. Outro aspecto que vale a pena lembrar é a temporalidade quanto ao uso da informação, afinal uma informação obtida, analisada e processada de uma partida de futebol, certamente não será utilizada na partida em si, pois não haverá tempo hábil para isso. A difícil percepção e compreensão dos indivíduos em relação à importância da informação e de seu 
registro para a geração de conhecimento faz com que as organizações se desenvolvam de modo mais lento que as organizações de outros segmentos econômicos.

Por outro lado, algumas informações circulam nos fluxos formais, essas em sua maioria residem no ambiente tático, responsável por sistematizar e gerir atividades que subsidiam os níveis estratégico e operacional. A estrutura organizacional existente na maioria dos clubes de futebol brasileiros não favorece a formalização da informação e, portanto, dificulta a geração de conhecimento. Por mais que exista uma corrente da sociedade esportiva que defenda a profissionalização dos clubes de futebol, ainda não há maturidade dos donos e/ou investidores para tal.

Os diretores que gerenciam os clubes, geralmente, realizam essa função por amor ao clube, deixando muitas vezes de lado a racionalidade das ações. Dessa maneira, há a baixa percepção dos elementos que de fato são importantes para o crescimento do clube como, por exemplo, a gestão da informação e a gestão do conhecimento, pois quando observam o clube, olham apenas os acontecimentos que ocorrem dentro do campo, ignorando na maioria das vezes qualquer ação no contexto interno ao clube. Assim, os clubes encontram dificuldade de gestão, dado que não é incomum encontrar uma organização esportiva vitoriosa, campeã de vários torneios, mas que a despeito disso possui um grande déficit financeiro.

\section{CONSIDERAÇÕES FINAIS}

Buscou-se demonstrar a importância do uso da informação no contexto esportivo, bem como a delimitação das informações esportivas relacionadas aos clubes de futebol. Dessa maneira, conceder importância à informação esportiva como importante componente responsável por propiciar diferenciais competitivos, visando gerar vantagem competitiva passa ser ponto de inicial e principal aspecto no contexto do esporte.

Considerando os aspectos conceituais sobre informação no contexto da Gestão da Informação (Gl), compreendeu-se que para a utilização da informação esportiva é necessário reconhecer os ambientes (interno e externo), bem como as principais fontes de informação, processos imprescindíveis para aproveitamento 
pleno das informações que trafegam nos fluxos formais e informais das organizações esportivas.

Partindo-se do modelo de estrutura organizacional proposto por Mintzberg (1995), que destaca 5 (cinco) níveis organizacionais: núcleo operacional, linha intermediária, cúpula estratégica, tecnoestrutura e assessoria de apoio. Usando como parâmetro o modelo proposto por Mintzberg (1995), identificou que para um melhor aproveitamento da informação por estas organizações, é necessário que o Clube possua em sua estrutura organizacional o profissional da informação que, por sua vez, será responsável por todas as atividades relacionadas à informação da organização esportiva (Figura 3).

Figura 3 - Proposta de estrutura organizacional para um clube de futebol de pequeno porte.

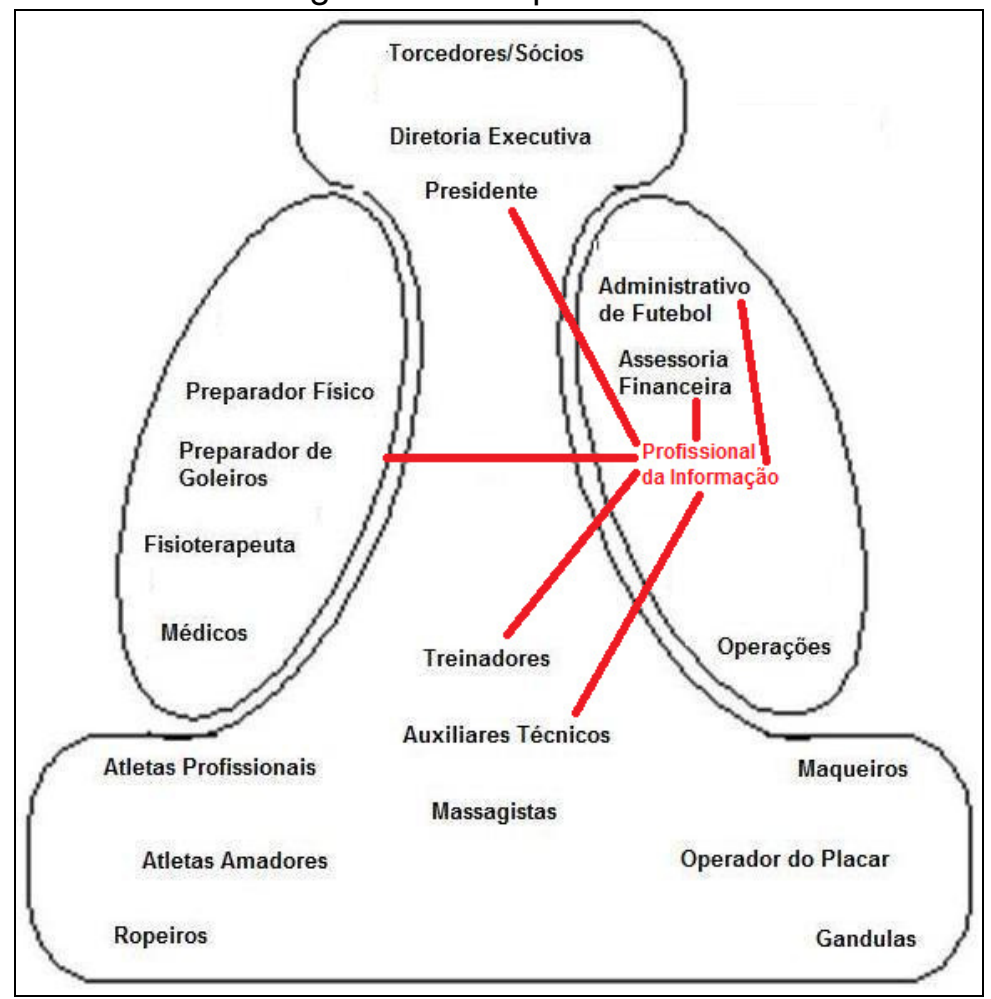

Fonte: Jorge e Valentim (2011, p. 125).

A principal atividade do profissional da informação refere-se ao gerenciamento e mediação da informação para todos os níveis organizacionais, apoiando as distintas atividades desenvolvidas no âmbito do clube. Esse profissional atuaria como um elemento estratégico na estrutura organizacional do clube, porquanto a atuação como gestor e mediador de informações nesse cenário é essencial. 
O profissional da informação por meio das atividades informacionais elaboraria uma base de dados com informações relevantes para o clube, bem como desenvolveria diferentes serviços e produtos informacionais customizados para os distintos níveis organizacionais que, por sua vez, subsidiariam o processo decisório e o planejamento de estratégias de ação de curto, médio e longo prazo. Além disso, seria responsável por desenvolver uma cultura informacional nos diferentes níveis da organização, processo que permitiria a criação de valores, crenças, ritos e artefatos no que tange a importância da informação para a organização esportiva.

Evidencia-se de suma importância a organização esportiva considerar todos os tipos de informação que estão inseridas nesse contexto, independente do suporte ou fluxo (formal ou informal).

Destaca-se que parte das informações técnicas é gerada em tempo real e não é registrada em nenhum suporte físico ou digital, tramitando em fluxos informais durante os treinamentos e partidas, ou seja, estão relacionadas diretamente com as operações dos clubes de futebol. Com a identificação, captura, seleção, uso e disseminação de informações durante as partidas e treinamentos, é possível tomar decisão rápida e assertiva que, por sua vez, pode proporcionar vantagem competitiva imediata.

Nessa perspectiva, o processo de tomada de decisão subsidiado por informações esportivas pode proporcionar diferenciais significativos, que podem ser decisivos em partidas e competições que o clube esta disputando. $O$ estabelecimento de inter-relações entre as informações esportivas formais e informais por parte do sujeito organizacional é essencial para a construção de conhecimento no contexto da organização.

É importante ressaltar que, a ausência do profissional da informação para a execução da gestão e mediação da informação deve ser considerada como um fator negativo para a obtenção de vantagem competitiva, principalmente se for levado em conta o contexto competitivo em que as organizações esportivas estão inseridas.

Além da necessidade do profissional da informação, identificou-se também a necessidade das organizações esportivas adotarem 0 uso de ferramentas responsáveis por conceder suporte no que se tange a um melhor aproveitamento das informações contidas em seu próprio ambiente, utilizando para isso a gestão da informação, a gestão do conhecimento e implementando o processo de inteligência 
organizacional responsáveis pela prospecção, análise, mediação, disseminação e uso de informações.

\section{REFERÊNCIAS}

BELLUZZO, Regina Celia Baptista. O acesso e uso da informação no esporte: uma competência cidadã. São Paulo. Revista Eletrônica do CEDOC/SEME, São Paulo, v. 1, n. esp., dez. 2009. Disponível em:

$<$ http://www.revistacedocseme.prefeitura.sp.gov.br/

images/CEDOC/oacessoeusodainformacaonoesporte.pdf>. Acesso em: $12 \mathrm{dez}$.

2012.

BOTELHO Maria Antonia, MONTEIRO, Ana Maria, VALLS, Valéria. A gestão do conhecimento esportivo: a experiência da biblioteca da Seme. Revista Ciência da Informação, Brasília, v. 36, n. 1, p. 175-188, jan./abr. 2007.

DAVENPORT, Thomas H.; HARRIS, Jeanne G. Competição analítica. Rio de Janeiro: Campus, 2007.

DAVENPORT, Thomas H.; PRUSAK, Laurence. Ecologia da informação: por que só a tecnologia não basta para o sucesso na era da informação. São Paulo: Futura, 1998.

JORGE, Carlos Francisco Bitencourt; VALENTIM, Marta Ligia Pomim. O profissional da informação no contexto da gestão esportiva: clubes de futebol, uma proposta para o Marília Atlético Clube. Revista EDICIC, Marília, v. 1, n. 3, p. 112-126, Jul./Sep. 2011. Disponível em: <http://www.edicic.org/revista/>. Acesso em: 21 dez.2011.

MINTZBERG, Henry. Criando organizações eficazes: estruturas em cinco configurações. São Paulo, Atlas, 1995.

MONTEIRO, Ana Maria Rodrigues Carvas da Costa; BOTELHO, Maria Antonia Gaviolli Mendes. A importância do trabalho com a informação jurídica esportiva na cidade de São Paulo. CRB-8 Digital, São Paulo, v. 2, n. 2, p. 55-65, set., 2009. Disponível em: <http://revista.crb8.org.br/index.php/crb8digital/article/view/7/7>. Acesso em: 16 jun. 2012.

SIMÕES, Roberto Porto. Futebol e informação: driblando incertezas. Porto Alegre: EDIPUCRS, 2009.

VALENTIM, Marta Ligia Pomim. Inteligência competitiva em organizações: dado, informação e conhecimento. DataGramaZero, Rio de Janeiro, v.3, n.4, ago. 2002. Disponível em: <http://www.dgz.org.br/ago02/F_l_art.htm>. Acesso em: 15 jan. 2012. 
. Processo de inteligência competitiva organizacional. In: VALENTIM, Marta Ligia Pomim. (Org.). Informação, conhecimento e inteligência organizacional. 2. ed. Marília: FUNDEPE, 2006. p. 9-24.

Title

Information and sport: the sports information and its relationship with football clubs

\begin{abstract}
Introduction: Presents information concepts and its use in the sporting context. Discusses the relationship between information and sporting environment, specifically in soccer clubs, defining it as sports information.

Objective: Describes about sports information, their main types, sources and environments, seeking a greater understanding of this kind of information. Analyzes the relationship between information and sporting environment, specifically in soccer clubs. Explains the information behavior in this type of organization and the impact on decision-making processes.

Methodology: Was realize a bibliographic research about the themes aligned to direct observation process in the activities carried out by a soccer club.

Results: Presents results related to information use in decision-making at different levels of a soccer club.

Conclusion: Demonstrates the importance of information using in the sporting context as well as the division of sports information related to soccer clubs. Highlights the sports information as an important component, responsible for providing competitive advantages, aimed at generating competitive advantage in the sport context.
\end{abstract}

Keywords: Sport information. Competitive advantages. Competitive intelligence. Soccer clubs.

\title{
Título
}

Información y deporte: La información deportiva y su relación con los clubes de fútbol

\section{Resumen}

Introducción: Presenta conceptos acerca de la información y su uso en el contexto deportivo. Discute la relación entre la información y el ambiente deportivo, específicamente en los clubes de fútbol, definiéndola como información deportiva.

Objetivo: Describe la tipología de la información deportiva, sus principales tipos, fuentes y ambientes, buscando una mayor comprensión de este tipo de información. Analiza la relación entre la información y ambiente deportivo, específicamente en los clubes de fútbol. 
Explica el comportamiento de información en este tipo de organización y el impacto para los procesos de toma de decisiones.

Métodos: Se realizó una búsqueda bibliográfica en los temas de investigación en línea con el proceso de observación directa en las actividades realizadas por un equipo de fútbol.

Resultados: Se presentan los resultados relacionados al uso de la información en la toma de decisiones en los diferentes niveles de un club de fútbol.

Conclusión: Se demuestra la importancia de utilizar la información en el contexto deportivo, así como la delimitación de la información deportiva en relación a los clubes de fútbol. Destaca la información deportiva como un componente importante, responsable de proporcionar ventajas competitivas, orientadas a generar una ventaja competitiva en el contexto del deporte.

Palabras-Clave: Información del deporte. Ventajas competitivas. Inteligencia competitiva. Los clubes de fútbol.

Recebido em: 10.09 .2014

Aceito em: 26.05.2015 